TITLE:

\title{
Spectrocolourimetry visualized differences in sexual skin colouration in macaques.
}

$\operatorname{AUTHOR}(S):$

Ono, Eiri; Suzuki, Juri; Ishida, Takafumi

CITATION:

Ono, Eiri ... [et al]. Spectrocolourimetry visualized differences in sexual skin colouration in macaques.. Folia primatologica 2015, 86(3): 178-186

ISSUE DATE:

2015-05

URL:

http://hdl.handle.net/2433/201386

RIGHT:

(c) 2015 S. Karger AG, Basel; This is not the published version. Please cite only the published version.; この論文は出版社版でありません。引用の 際には出版社版をご確認ご利用ください。 
1 Spectrocolorimetry visualized differences in sexual skin coloration in macaques

2 Eiri Ono $^{1}$, Juri Suzuki ${ }^{2}$ and Takafumi Ishida ${ }^{1}$

3

$4 \quad{ }^{1}$ Department of Biological Sciences, Graduate School of Science, University of Tokyo, 7-3-1

5 Hongo, Bunkyo-ku, Tokyo 113-0033, Japan

$6 \quad{ }^{2}$ Primate Research Institute, Kyoto University, Inuyama, Aichi, Japan

7

8 The number of words

94,106 words

10

11 Corresponding author

12 Eiri Ono, Unit of Human Biology and Genetics, Department of Biological Sciences, Graduate

13 School of Science, University of Tokyo, 7-3-1 Hongo, Bunkyo-ku, Tokyo 113-0033, Japan

14 E-mail: onoeiri@bs.s.u-tokyo.ac.jp

15 Phone number: +81-3-5841-4496

16 Fax number: +81-3-3818-7547

17

18 Running Head

19 Spectrocolorimetry of macaque sexual skin

21 Keywords

22 Macaca fuscata, Macaca mulatta, sexual skin, spectorocolorimetry, CIELAB space 


\section{Abstract}

26 Females of some catarrhines develop conspicuous sexual skin transformation in their hindlimbs. Among the macaques, one of the radiated and adapted catarrhine groups with diversified sexual skin transformation, differences in sexual skin coloration between the Japanese macaques Macaca fuscata and rhesus macaques Macaca mulatta have not been quantitatively analyzed. In this study, sexual skin coloration of these macaques was spectrocolorimetrically measured in the non-mating season (NMS) and mating season (MS) and represented in the CIELAB space with the variables of $L^{*}, a^{*}$ and $b^{*}$. In the Japanese macaques, the average $\pm \mathrm{SD}$ of $L^{*}, a^{*}$, and $b^{*}$ was $53.61 \pm 3.31,11.51 \pm 4.57$ and $6.66 \pm 2.25$ in the NMS, and 46.60 $\pm 2.78,19.97 \pm 2.99$ and $8.80 \pm 1.34$ in the MS, respectively; while in the rhesus macaques, the average of $L^{*}, a^{*}, b^{*}$ was $60.09 \pm 3.96,5.99 \pm 4.59$ and $5.83 \pm 2.37$ in the NMS, and $52.70 \pm 6.54,13.62 \pm 6.86$ and $8.07 \pm 1.43$ in the MS, respectively. Sexual skin of Japanese macaques was consistently much redder (larger $a^{*}$ ) and darker (smaller $L^{*}$ ) than that of rhesus macaques. The smaller $L^{*}$ suggested the more dermal melanin content in the Japanese macaques. These closely related macaque species have similar but distinct sexual skin coloration. Spectrocolorimetry is thus useful to suggest histo-physiological background of coloration. 


\section{Introduction}

Females of some catarrhines develop conspicuous transformation around the perineal skin in their hindlimbs [Collings, 1926; Dixson, 1983; Anderson and Bielert, 1994; Nunn, 1999; Higham et al., 2010]; this "sexual skin” is thought to be tightly involved in socio-sexual signaling [Wickler, 1967; Gerald et al., 2007; Bradley and Mundy, 2008]. Changes in the sexual skin are simply referred as swelling and coloration. Exaggerated swellings are typical for females in the species with a multimale-multifemale social structure [Nunn, 1999]. Because the swelling reaches its maximum size at around the time of ovulation in the baboons [Higham et al., 2008], mandrills [Setchell and Wickings, 2004], chimpanzees [Deschner et al., 2004] and macaques [Higham et al., 2012], sexual skin swelling is thought to indicate female fertility. On the other hand, sexual skin coloration comprises several facets in the context of fertility and mating behavior [Czaja et al., 1975; Baulu, 1976; Waitt et al., 2006; Higham et al., 2008; Dubuc et al., 2009; Wallner et al., 2011; Watson et al., 2012].

The macaques comprising more than 20 species have radiated and adapted to various environments [Thierry, 2010]. Changes in the sexual skin are also diversified among them. Japanese macaques (Macaca fuscata) and rhesus macaques (M. mulatta) belong to the fascicularis lineage and the former live under various environments from warm to cool temperate zones in Japan, whereas the latter inhabit various environments in the mainland Asia such as India, China and southeast Asia. These two macaques share similar reproductive features [reviewed in Thierry, 2010]; for example, ovarian cycle length (Japanese macaques: 26.5 days; rhesus macaques: 28.3 days), a multimale-multifemale social structure, multi-mounting behavior and seasonal breeding but age at first birth delays in the Japanese macaques (Japanese macaques: five years; rhesus macaques: four years). Sexual swellings were recognized in adolescent females of both species [Anderson and Bielert, 1994], and females' red sexual skin draws male attention [Waitt, et al., 2006; Wallner et al., 2011]. However, sexual skin of the Japanese macaques swells less obviously and is much redder than 

4

that of the rhesus macaques [observed by JS], differences in sexual skin coloration between the two species have not been quantitatively analyzed; these backgrounds prompted us to introduce spectrocolorimetry into the sexual skin coloration study.

Visual observation, digital photography, and spectrocolorimetry have been used for skin color measurement [Stevens et al., 2009]. Among them, spectrocolorimetry obtaining direct color data is applicable to reared animals and the obtained color data are objective without interferences such as stray light. For the evaluation of the obtained color data, there are two major protocols; a model of common color space, such as the CIELAB space that was developed for human color vision and a Receptor-Noise Limited (RNL) model [Vorobyev and Osorio, 1998] that stands species-specific data on the peripheral visual system. Data for species-specific visual system were not available in the Japanese macaques yet but were already obtained for the rhesus macaques [Bowmaker et al., 1978]. The CIELAB space gave great insights into the relationship between skin color and pigmentation, such as by melanin and hemoglobin, in humans [Weatherall and Coombs, 1992; Zonios et al., 2001; Alaluf et al., 2002a; Stephen et al., 2009]; in addition, it was proved in the mandrills (Mandrillus sphinx), a member of the papionines, that the CIELAB model gave qualitatively similar results to those in the RNL model [Renoult et al., 2011]. The CIELAB model is thus considered a useful tool to compare skin color in the catarrhines who have a uniform color vision system similar to that of humans [Jacobs and Deegan, 1999; Changizi et al., 2006].

In this study, we aimed to evaluate and distinguish sexual skin coloration objectively in closely related macaques categorized in the fascicularis group whose sexual skin appears similar [Nunn, 1999]. We thus obtained color profiles of sexual skin of the Japanese macaques and rhesus macaques with a spectrocolorimeter and analyzed them in the CIELAB space.

\section{Materials \& Methods}


Subjects

Twelve female Japanese macaques (Macaca fuscata) aged from four to six years and 13 female rhesus macaques (Macaca mulatta) aged from three to five years reared at

100 Primate Research Institute, Kyoto University, Inuyama, Aichi, Japan were recruited for this study. When we started the data collection in the non-mating season, reddening and swelling of sexual skin of the subjects were not recognized; they were likely to be menarche. We measured their color profiles in July (non-mating season: NMS) and October (mating season: MS) 2010, or in August (NMS) and November (MS) 2011. Two of 12 Japanese macaques were studied in 2010 and the other 10 were in 2011, while six of 13 rhesus macaques were in 2010 and the other seven were in 2011. The detailed information of the subjects is in the online supplementary table. This study followed the Guidelines for Care and Use of non-Human Primates, Primate Research Institute, Kyoto University, and was approved by the Ethics committee of animal experiments of the institute.

\section{Color measurements}

To measure sexual skin coloration, one spot was selected at 2-3 cm under the ischial callosity of each side (two spots for each subject in one season, figure 1). Prior to the measurement, the subjects were anesthetized with ketamine hydrochloride $(50 \mathrm{mg} / \mathrm{mL}$

115 Ketalar ${ }^{\circledR}$, Sankyo-Parke-Davis \& Co., Inc., Japan, 2.5 mg/kg) and medetomidine hydrochloride (Domitor ${ }^{\circledR}$ Meiji Seika Kaisha, Ltd. Tokyo, Japan, $0.1 \mathrm{mg} / \mathrm{kg}$ ), and then the measurement spots were cleaned and shaved. The selected spots were measured in July (NMS) and in October (MS) 2010, also in August (NMS) and in November (MS) 2011. A

119 single color measurement for each spot was conducted with a MINOLTA Spectrocolorimeter

120 CG-411C (for the CIE D65/10 illuminant/observer condition). Three variables in the

121 CIELAB color system, $L^{*}, a^{*}$, and $b^{*}$ were extracted for each measurement. The average values of $L^{*}, a^{*}$ and $b^{*}$ for each subject were calculated. The variable $L^{*}, a^{*}$ and $b^{*}$ represents 
123 position on the light-dark, red/magenta-green, and yellow-blue axis, respectively. The $L^{*}$

124 ranges from 100 to 0 , whereas the $a^{*}$ and $b^{*}$, can take any figure theoretically, ranging from

125 about 100 to -100 in general.

126 Antidote to medetomidine, atipamezole hydrochloride (Domitor ${ }^{\circledR}$ Meiji Seika

127 Kaisha, Ltd. Tokyo, Japan, $0.5 \mathrm{mg} / \mathrm{kg}$ ), was administered for fully recovering after the

128 measurement.

129

130

\section{Data analysis}

The data in July 2010 and August 2011 were combined for the NMS, while the data in October 2010 and November 2011 were combined for the MS. Changes in sex skin coloration between NMS and MS were tested with the paired t-test. The differences between the two species in each season were tested with the paired t-test, two-sample t-test and Welch's two-sample t-test if necessary. The relationship between the seasonal differences (MS - NMS) in $L^{*}$ and $a^{*}$ was analyzed with a linear regression. P value less than $0.05(\mathrm{p}<0.05)$ was considered significant.

\section{Results} MS is visualized in figure 2 with the $L^{*}, a^{*}$, and $b^{*}$ variables. In the Japanese macaques, the average \pm SD of $L^{*}, a^{*}$, and $b^{*}$ was $53.61 \pm 3.31,11.51 \pm 4.57$ and $6.66 \pm 2.25$ in the NMS, and $46.60 \pm 2.78,19.97 \pm 2.99$ and $8.80 \pm 1.34$ in the MS, respectively; while in the rhesus macaques, the average of $L^{*}, a^{*}, b^{*}$ was $60.09 \pm 3.96,5.99 \pm 4.59$ and 5.83 \pm 2.37 in the NMS, and $52.70 \pm 6.54,13.62 \pm 6.86$ and $8.07 \pm 1.43$ in the MS, respectively. In the MS, decreases in the $L^{*}$ and increases in the $a^{*}$ and $b^{*}$ were consistently observed in each subject of both the Japanese and rhesus macaques (table 1). 

in figure 2. In both seasons, the significant species differences were observed for the variable

152

153

154 $L^{*}($ NMS: $\mathrm{t}=-4.22, \mathrm{p}<0.001$ by two-sample t-test; $\mathrm{MS}: \mathrm{t}=-3.08, \mathrm{p}<0.01$ by Welch's two-sample t-test) and the variable $a^{*}(\mathrm{NMS}: \mathrm{t}=-3.01, \mathrm{p}<0.01$ by two-sample $\mathrm{t}$-test; $\mathrm{MS}: \mathrm{t}=$ 3.04, $\mathrm{p}<0.01$ by Welch's two sample t-test) but not for the variable $b^{*}$ (NMS: $\mathrm{t}=0.89, \mathrm{p}>$ 0.05 by two-sample t-test; MS: $\mathrm{t}=1.31, \mathrm{p}>0.05$ by two-sample $\mathrm{t}$-test). In both species, the significant seasonal differences were observed for the variable $L^{*}$ (Japanese macaques: $\mathrm{t}=$ 6.55, $\mathrm{p}<0.001$ by paired t-test; rhesus macaques: $\mathrm{t}=6.48, \mathrm{p}<0.001$ by paired t-test), the variable $a^{*}$ (Japanese macaques: $\mathrm{t}=-6.20, \mathrm{p}<0.001$ by paired $\mathrm{t}$-test; rhesus macaques: $\mathrm{t}=$ -8.41, $\mathrm{p}<0.001$ by paired t-test) and the variable $b^{*}$ (Japanese macaques: $\mathrm{t}=-3.58, \mathrm{p}<0.01$ by paired t-test; rhesus macaques: $\mathrm{t}=-3.76, \mathrm{p}<0.01$ by paired $\mathrm{t}$-test).

The correlation coefficient between the seasonal differences in $L^{*}$ and $a^{*}$ was -0.94 ( $\left.r^{2}=0.89, \mathrm{p}<0.001\right)$ in the Japanese macaques, and $-0.82\left(r^{2}=0.67, \mathrm{p}<0.001\right)$ in the rhesus macaques.

\section{Discussion}

Sexual skin coloration of female Japanese macaques and rhesus macaques was spectrocolorimetrically measured and represented in the CIELAB space with which we can biologically interpret sexual skin coloration (table 1 and fig. 2). We analyzed the obtained color values from two aspects: seasonal change and species difference. Seasonal changes in the sexual skin coloration in the Japanese macaques and rhesus macaques were more or less similar; that is, sexual skin became darker, redder and yellower in the MS compared to NMS in both species. In detail, we also found that sexual skin of Japanese macaques was much redder (larger $a^{*}$ ) and darker (smaller $L^{*}$ ) than that of rhesus macaques through the NMS and MS (fig. 2); this is consistent with the general observations that sexual skin of Japanese 
macaques appears to be redder than that of rhesus macaques. In terms of CIELAB values, similar dynamic changes in $L^{*}, a^{*}$ and $b^{*}$ were observed and it is thus conceivable that all the color values in the NMS as well as in the MS in both macaques are under the control of the same factor(s). The sexual skin color in the NMS is considered to represent the basic conditions without the surge of reproductive hormones, such as estrogen and progesterone [Nozaki et al., 1995]. Since in the NMS the variable $L^{*}$ and $a^{*}$ but not $b^{*}$ were significantly different between the two species (fig. 2), it is suggested that the presence of different basic conditions that give lighter sexual skin to the rhesus macaques and redder sexual skin to the Japanese macaques. We thus demonstrate that the closely related these macaque species have similar but distinct sexual skin coloration.

Among various factors modifying skin coloration, two major pigments, melanin and hemoglobin, are of our interest. Melanin content modifies all the three color values, in particular, $L^{*}$ [Takiwaki, 1998; Alaluf et al., 2002b]. In human skin coloration, changes in $L^{*}$ is mainly due to epidermal melanin content [Alaluf et al., 2002b] that is negatively correlated with the $L^{*}$ among human population [Alaluf et al., 2002a]. The seasonal decrease in the $L^{*}$ in the Japanese and rhesus macaques may be attributed to the increase in dermal melanin content. The lower $L^{*}$ values in the Japanese macaques both in the NMS and MS indicate more dermal melanin contents in the Japanese macaques. Melanin production is induced by ultra-violet (UV) light [Pathak et al., 1962; Jablonski and Chaplin, 2000; Jablonski and Chaplin, 2010] and the epidermal melanin content is subject to adaptive responses to UV light intensity; however, 17-ß estradiol for example stimulates melanocyte tyrosinase activity in the human skin [Ranson et al., 1988; McLeod et al., 1994]. We thus cannot rule out possible contributions of other factor(s) to the melanization, and effects of estradiol on the dermal melanin content in macaques should be also elucidated to explain the consistently lower $L^{*}$ in the Japanese macaques.

The $a^{*}$ represents the red-green color axis and the higher $a^{*}$ values were observed in the Japanese macaques in the NMS and MS. In humans, red color of the skin is mainly due to 
204 the superficial vascular plexus in the upper dermis [Takiwaki, 1998; Alaluf et al., 2002b] 205 where reproductive hormones also play certain roles such as improved vascularization by estrogens [Thornton, 2002]. As the reproductive hormones can modulate blood vessels in the sexual skin in the MS [Czaja et al., 1977], the increases in $a^{*}$ in the MS may be due to vascularization and/or vasodilatation in the Japanese and rhesus macaques. Consistently lower melanin contents in the rhesus macaques were indicated by their higher $L^{*}$ values both in the NMS and MS. This may correspond to the observation by Montagna et al. (1964) that rhesus macaque has little melanin in the epidermis as well as to the prediction by Collings (1926) that the sexual skin reddening is not due to the pigmentation but to the dynamics of sub-epidermal blood vessels. We conclude that melanin contents support the baseline of the $a^{*}$, whereas the increased $a^{*}$ in the MS is due to blood hemoglobin in both species. The seasonal differences in $L^{*}$ and $a^{*}$ were highly correlated in both species (fig. 3). The high correlation indicates $L^{*}$ and $a^{*}$ are mostly under the same factors to change, namely, melanin and blood hemoglobin. The $r^{2}$ of regression line in the rhesus macaques was lower than that in the Japanese macaques. It indicates other factor(s) of the coloration in the rhesus macaques, for example, sexual swelling. The structural change of sexual skin may also modify the coloration.

It has been reported that adolescent females of both Japanese and rhesus macaques exhibit sexual swellings [Anderson and Bielert, 1994]. However, no Japanese macaques aged from four to six years exhibited sexual swelling, while 11 of the 13 rhesus macaques aged from three to five years did in this study. If the sexual skin coloration and swelling play a role in socio-sexual signaling, possible compensation of their bright red coloration for the lack of sexual swelling should be taken into consideration; it has been reported that hindlimb bright coloration might contain meaningful physiological information in Japanese macaques [Wallner et al., 2011].

For the analyses of spectrocolorimetric data of mandrills, the RNL model gave 
231 data by the RNL model, which were consistent with those in the CIELAB model (data not 232 shown) but the CIELAB model gave higher resolutions. The CIELAB model is suitable for 233 such coloration studies; however, the RNL model that is based on the species-specific visual system may have a potential to approach to understand cognitive consequences in the receiver of color signals. In conclusion, our study has opened objective and quantitative color measurements of sexual skin coloration and demonstrated their similar and dissimilar profiles in the closely related two macaque species. More detailed histological and molecular studies for these macaques' sexual skin will provide evolutionary insights in the mechanism of the sexual skin development in the primates. Spectrocolorimetry should help a further research on species-specific, sex-specific, and age-related coloration in various body parts especially bare skin among primates.

\section{Acknowledgments}

We are grateful to Prof. Kenichi Aoki, Department of Biological Sciences, University of Tokyo for his generous permission to use a spectrocolorimeter. We also thank Prof. Roscoe Stanyon for his comments on this manuscript. This work was supported by the Cooperation Research Program of Primate Research Institute, Kyoto University.

\section{References}

Alaluf S, Atkins D, Barrett K, Blout M, Carter N, Heath A (2002). Ethnic variation in melanin content and composition in photoexposed and photoprotected human skin. Pigment Cell Research 15:112-118. 
258

259

260

261

262

263

264

265

266

267

268

269

270

271

272

273

274

275

276

277

278

279

280

281

282

283

284

epidermal melanin on objective measurements of human skin colour. Pigment Cell Research 15: $119-126$.

Anderson CM, Bielert CF (1994). Adolescent exaggeration in female catarrhine primates. Primates 35: 283-300.

Baulu J (1976). Seasonal sex skin coloration and hormonal fluctuations in free-ranging and captive monkeys. Hormones and Behavior 7: 481-494.

Bowmaker JK, Dartnall HJ, Lythgoe JN, Mollon JD (1978). The visual pigments of rods and cones in the rhesus monkey, Macaca mulatta. Journal of Physiology 274: 329-348. Bradley BJ, Mundy NI (2008). The primate palette: The evolution of primate coloration. Evolutionary Anthropology: Issues, News, and Reviews 17: 97-111.

Brandon-Jones D, Eudey AA, Geissmann T, Groves CP, Melnick DJ, Morales JC, Shekelle M, Stewart CB (2004). Asian primate classification. International Journal of Primatology 25:97-164.

Changizi MA, Zhang Q, Shimojo S (2006). Bare skin, blood and the evolution of primate colour vision. Biology letters 2: 217-21.

Collings MR (1926). A study of the cutaneous reddening and swelling about the genitalia of the monkey, Macacus rhesus. The Anatomical Record 33: 271-287.

Czaja JA, Eisele SG, Goy RW (1975). Cyclical changes in the sexual skin of female rhesus: relationships to mating behavior and successful artificial insemination. Federation Proceedings 34: 1680-4.

Deschner T, Heistermann M, Hodges K, zBoesch C (2004). Female sexual swelling size, timing of ovulation, and male behavior in wild West African chimpanzees. Hormones and Behavior 46:204-215.

Dixson A (1983). Observations on the evolution and behavioral significance of 'sexual skin' in female primates. In Advances in the Study of Behavior Vol. 13 (Rosenblatt JS, Hinde RA, Beer C, Busnel MC eds.), pp 63-106.

Dubuc C, Brent LJN, Accamando AK, Gerald MS, MacLarnon A, Semple S, 
285

286

287

288

289

290

291

292

293

294

295

296

297

298

299

300

301

302

303

304

305

306

307

308

309

310

311

Heistermann M, Engelhardt A (2009). Sexual skin color contains information about the timing of the fertile phase in free-ranging Macaca mulatta. International Journal of Primatology 30: 777-789.

Gerald MS, Waitt C, Little AC, Kraiselburd E (2007). Females pay attention to female secondary sexual color: an experimental study in Macaca mulatta. International Journal of Primatology 28: 1-7.

Higham JP, MacLarnon AM, Ross C, Heistermann M, Semple S (2008). Baboon sexual swellings: information content of size and color. Hormones and Behavior 53: 452-62. Higham JP, Brent LJN, Dubuc C, Accamando AK, Engelhardt A, Gerald MS, Heistermann M, Stevens M (2010). Color signal information content and the eye of the beholder: a case study in the rhesus macaque. Behavioral ecology 21: 739-746.

Higham JP, Heistermann M, Saggau C, Agil, Muhammad PFD, Engelhardt A (2012). Sexual signalling in female crested macaques and the evolution of primate fertility signals. BMC Evolutionary Biology 12: 89.

Jablonski N, Chaplin G (2000). The evolution of human skin coloration. Journal of Human Evolution 39: 57-106.

Jablonski N, Chaplin G (2010). Human skin pigmentation as an adaptation to UV radiation. Proceedings of the National Academy of Sciences of the United States of America 107: 8962-8968.

Jacobs GH, Deegan JF (1999). Uniformity of colour vision in Old World monkeys. Proceedings of the Royal Society B: Biological Sciences 266:2023-8. doi: 10.1098/rspb.1999.0881

McLeod SD, Ranson M, Mason RS (1994). Effects of estrogens on human melanocytes in vitro. The Journal of Steroid Biochemistry and Molecular Biology 49: 9-14. Nozaki M, Mitsunaga F, Shimizu K (1995). Reproductive senescence in female Japanese monkeys (Macaca fuscata): age- and season-related changes in hypothalamic-pituitary-ovarian functions and fecundity rates. Biology of Reproduction 
52:1250-1257.

Pathak MA, Riley FJ, Fitzpatrick TB, Curwen WL (1962). Melanin formation in human skin induced by long-wave ultra-violet and visible light. Nature 193:148-150.

Ranson M, Posen S, Mason RS (1988). Human melanocytes as a target tissue for hormones: in vitro studies with 1 alpha-25, dihydroxyvitamin D3, alpha-melanocyte stimulating hormone, and beta-estradiol. Journal of Investigative Dermatology 91:593-8. Renoult JP, Schaefer HM, Sallé B, Charpentier MJE (2011). The evolution of the multicoloured face of mandrills: insights from the perceptual space of colour vision. PloS ONE 6: e29117.

Setchell JM, Wickings EJ (2004). Sexual swelling in mandrills (Mandrillus sphinx): a test of the reliable indicator hypothesis. Behavioral Ecology 15:438-445.

Stephen ID, Law Smith MJ, Stirrat MR, Perrett DI (2009). Facial skin coloration affects perceived health of human faces. International Journal of Primatology 30: 845-857.

Stevens M, Stoddard MC, Higham JP (2009). Studying primate color: towards visual system-dependent methods. International Journal of Primatology 30: 893-917.

Takiwaki H (1998). Measurement of skin color: practical application and theoretical considerations. The Journal of Medical Investigation 44:121-126.

Thierry B (2010). The macaques - a double-layered social organization. In: Primates in Perspective, 2nd ed. (Campbell C, Fuentes A, MacKinnon K, Bearder S, Stumpf R, eds.), pp 229-241. Oxford University Press.

Thornton MJ (2002). The biological actions of estrogens on skin. Experimental Dermatology 11: 487-502.

Tosi AJ, Morales JC, Melnick DJ (2000). Comparison of Y chromosome and mtDNA phylogenies leads to unique inferences of macaque evolutionary history. Molecular Phylogenetics and Evolution 17: 133-44.

Vorobyev M, Osorio D (1998). Receptor noise as a determinant of colour thresholds. Proceedings of the Royal Society B: Biological Sciences 265: 351-8. 
340 female secondary sexual color in male rhesus macaques. American Journal of Primatology 341 68: 738-44.

Wallner B, Aspernig D, Millesi E, Machatschke IH (2011). Non-lactating versus

343 lactating females: a comparison of sex steroids, sexual coloration, and sexual behavior in 344 Japanese macaques. Primates 52: 69-75.

Watson KK, Ghodasra JH, Furlong MA, Platt ML (2012). Visual preferences for sex

346 and status in female rhesus macaques. Animal Cognition 15: 401-7.

Weatherall IL, Coombs BD (1992). Skin color measurements in terms of CIELAB

348 color space values. Journal of Investigative Dermatology 99: 468-473.

Wickler W (1967). Socio-sexual signals and their intra-specific imitation among

350 primates. In Primate Ethology (Morris D eds.), pp 69-147. London, Weidenfeld and

351 Nicolson.

Zonios G, Bykowski J, Kollias N (2001). Skin melanin, hemoglobin, and light

353 scattering properties can be quantitatively assessed in vivo using diffuse reflectance

354 spectroscopy. Journal of Investigative Dermatology 117: 1452-7. 
357 Table 1. Sexual skin color of the Japanese and rhesus macaques represented with $L^{*}, a^{*}$ and $358 b^{*}$ variables.

$\begin{array}{llllllll}359 & \text { Subject } & & \text { NMS } & & & \text { MS } & \\ 360 & & L^{*} & a^{*} & b^{*} & L^{*} & a^{*} & b^{*} \\ 361 & \text { Mf 1 } & 53.31 & 9.21 & 5.64 & 51.56 & 12.67 & 8.63 \\ 362 & \text { Mf 2 } & 51.08 & 10.39 & 3.72 & 45.38 & 18.92 & 7.39 \\ 363 & \text { Mf 3 } & 55.39 & 15.45 & 9.88 & 49.79 & 20.33 & 8.78 \\ 364 & \text { Mf 4 } & 55.79 & 10.45 & 6.49 & 49.13 & 17.53 & 5.66 \\ 365 & \text { Mf 5 } & 52.50 & 17.49 & 8.63 & 47.39 & 22.92 & 9.18 \\ 366 & \text { Mf 6 } & 55.23 & 5.23 & 4.13 & 43.25 & 20.55 & 8.18 \\ 367 & \text { Mf 7 } & 57.08 & 10.85 & 7.50 & 49.26 & 18.31 & 8.97 \\ 368 & \text { Mf 8 } & 49.27 & 19.55 & 9.42 & 45.93 & 23.68 & 9.77 \\ 369 & \text { Mf 9 } & 50.89 & 13.30 & 6.31 & 44.51 & 19.33 & 9.43 \\ 370 & \text { Mf 10 } & 48.00 & 12.50 & 8.05 & 43.32 & 20.90 & 10.85 \\ 371 & \text { Mf 11 } & 55.99 & 9.92 & 7.30 & 45.67 & 21.56 & 10.16 \\ 372 & \text { Mf 12 } & 58.79 & 3.82 & 2.84 & 43.99 & 22.94 & 8.62 \\ 373 & \text { Mm 1 } & 64.47 & 2.43 & 6.44 & 58.94 & 4.87 & 6.13 \\ 374 & \text { Mm 2 } & 61.29 & 4.04 & 8.40 & 58.95 & 8.93 & 9.28 \\ 375 & \text { Mm 3 } & 62.14 & 0.72 & 6.35 & 53.34 & 9.41 & 8.91 \\ 376 & \text { Mm 4 } & 67.56 & -1.29 & -0.13 & 54.76 & 7.24 & 6.88 \\ 377 & \text { Mm 5 } & 58.88 & 5.95 & 6.72 & 49.26 & 15.62 & 7.03 \\ 378 & \text { Mm 6 } & 62.62 & 1.43 & 3.76 & 62.44 & 4.39 & 8.10 \\ 379 & \text { Mm 7 } & 61.40 & 5.37 & 5.24 & 59.79 & 10.14 & 8.29 \\ 380 & \text { Mm 8 } & 61.49 & 7.05 & 6.84 & 56.83 & 13.34 & 9.38 \\ 381 & \text { Mm 9 } & 54.53 & 13.85 & 8.90 & 45.49 & 22.85 & 8.10 \\ 382 & \text { Mm 10 } & 60.21 & 5.75 & 5.43 & 51.72 & 15.78 & 8.64 \\ 383 & \text { Mm 11 } & 54.51 & 11.70 & 7.64 & 42.61 & 25.30 & 11.08 \\ 384 & \text { Mm 12 } & 55.26 & 10.36 & 3.63 & 45.38 & 17.52 & 6.11 \\ 385 & \text { Mm 13 } & 56.87 & 10.48 & 6.61 & 45.69 & 21.71 & 7.01\end{array}$

387 Mf: Japanese macaque; Mm: rhesus macaque; NMS: non-mating season (July, 2010 and Aug, 388 2011); MS: mating season (October, 2010 and November, 2011) 


\section{$390 \quad$ Legend to figure 1}

391 Measurement spots were selected inside the yellow circles under ischial callosities.

392

\section{Legend to figure 2}

394 Species and seasonal differences in the sexual skin coloration.

395 The dashed lines represent the interspecific comparisons in each season. The black bold lines 396 indicate the means and the black circles indicate the deviated values.

$397 \quad * * * P<0.0001 ; * * P<0.001 ; * P<0.05$; NS: not significant.

398

$399 \quad$ Legend to figure 3

400 Correlation between the seasonal differences (MS-NMS) in $L^{*}$ and $a^{*}$ for the Japanese 401 macaques (Mf) and the rhesus macaques (Mm). 
figure 1

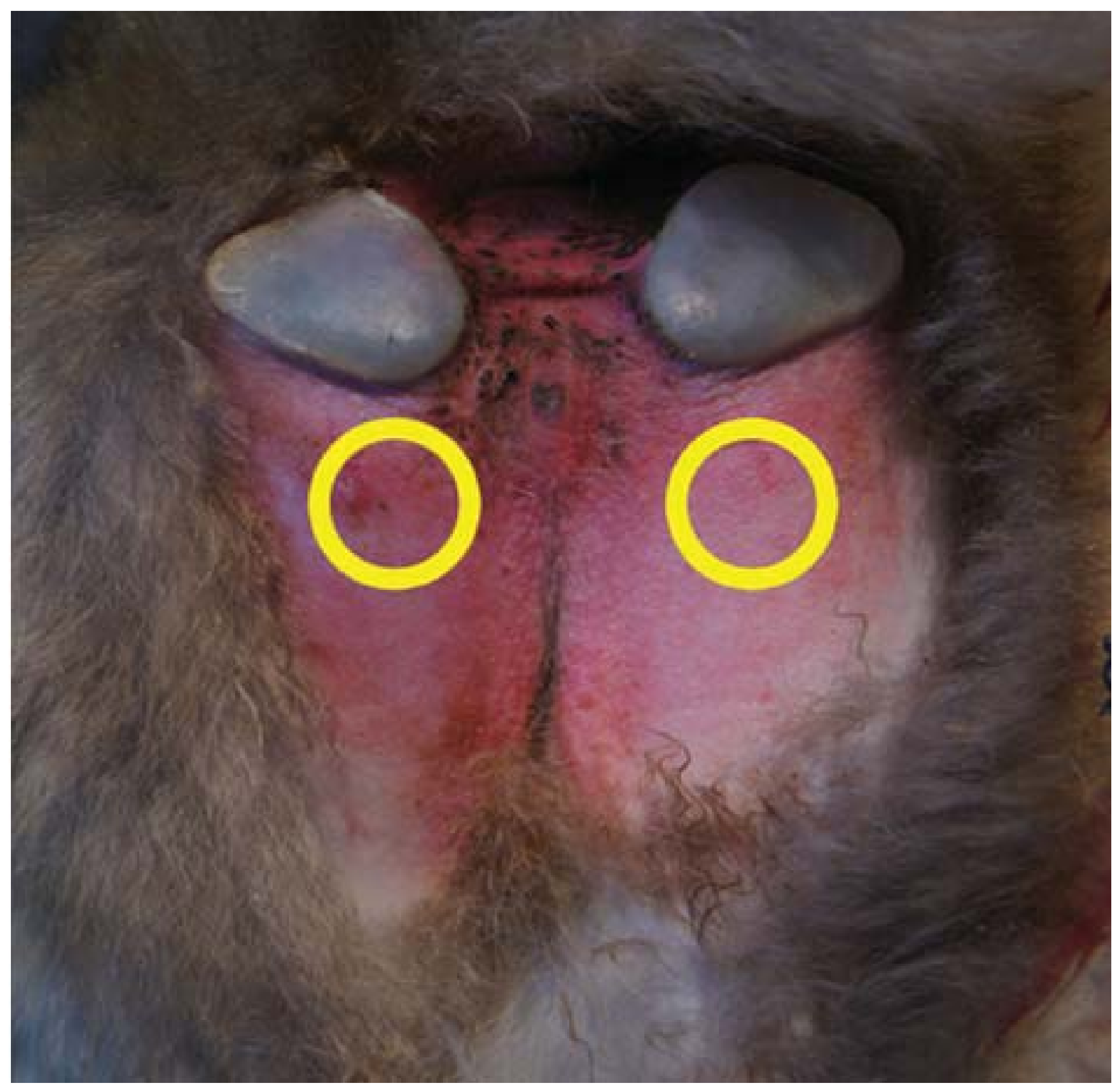




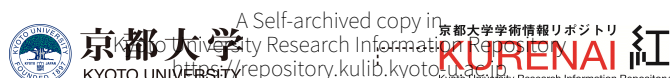

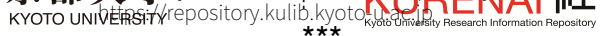

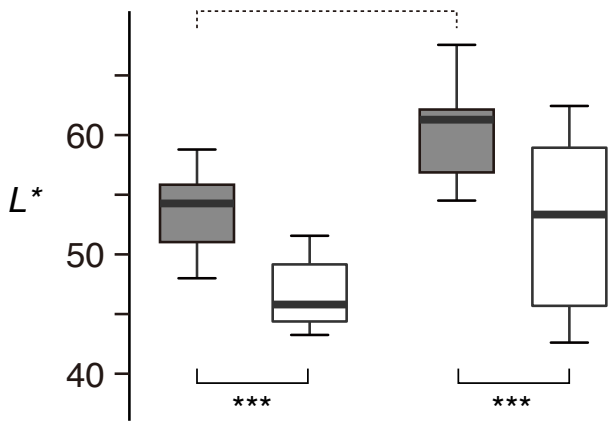

**

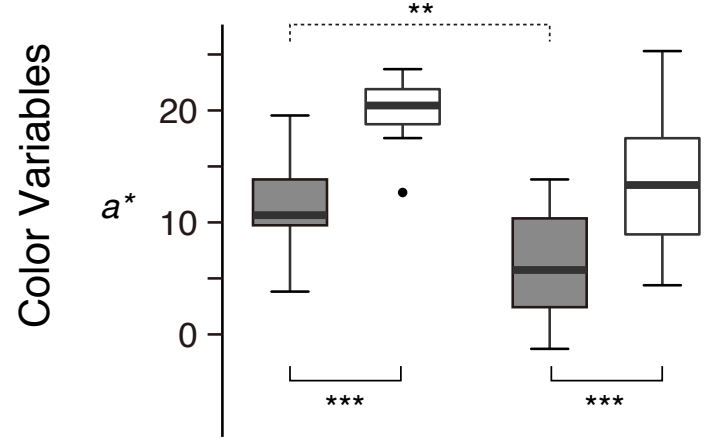

NS

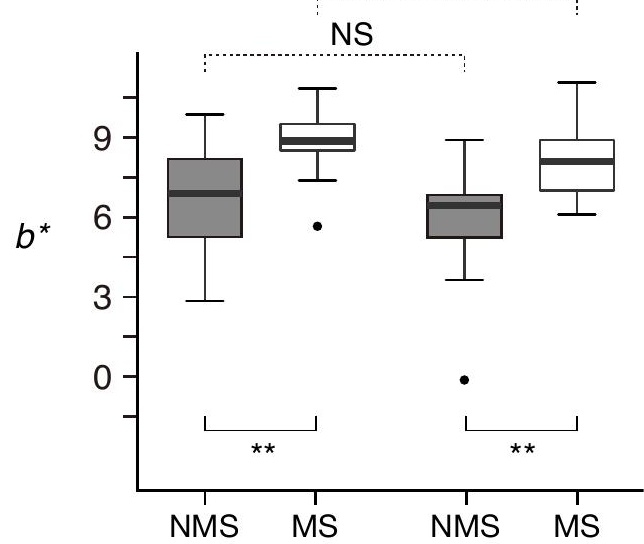

Japanese

Rhesus macaques

$n=12$

macaques

$n=13$ 


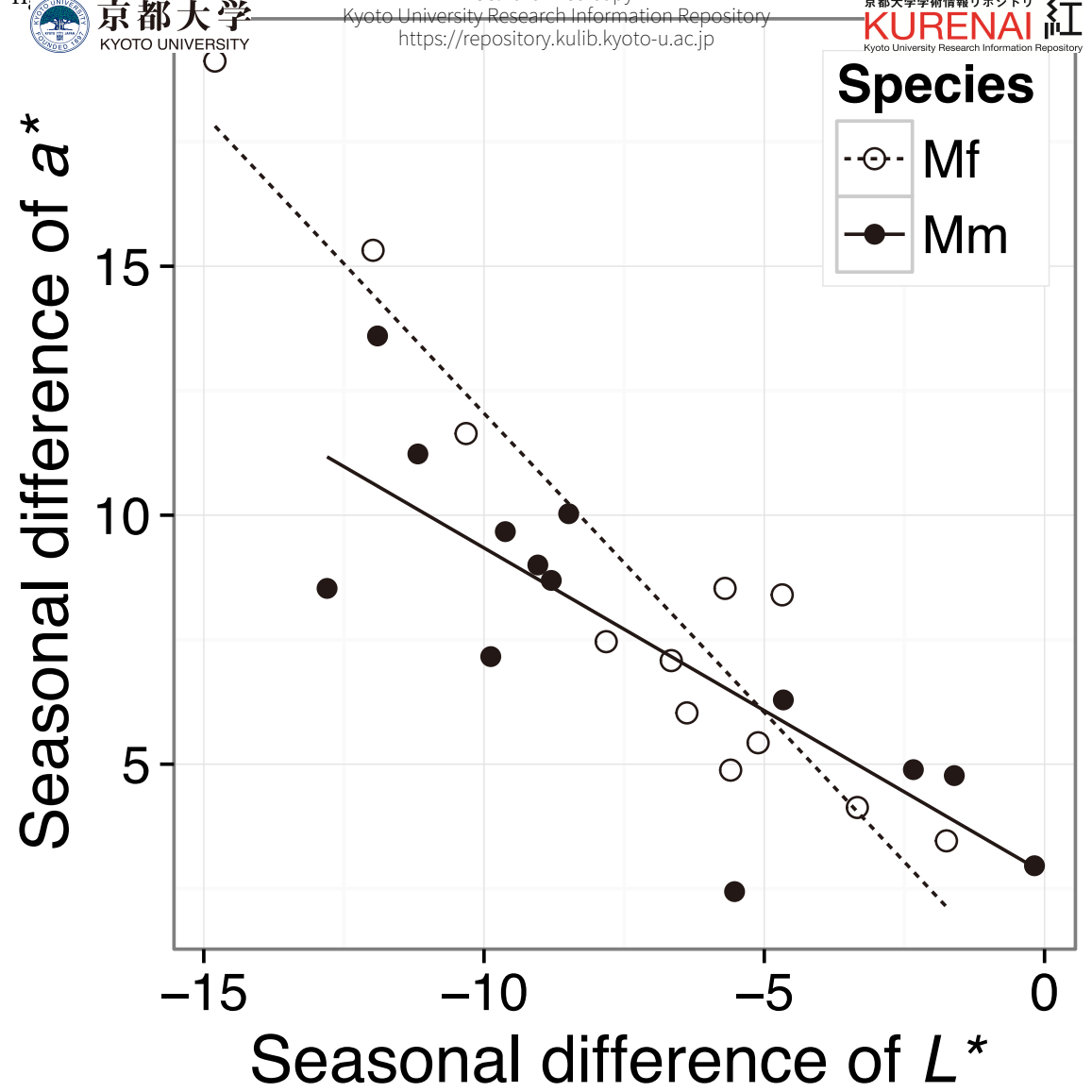

